\title{
INTERLEUKIN-15 INCREASES Paracoccidioides brasiliensis KILLING BY HUMAN NEUTROPHILS
}

Thesis: E. G. Tavian submitted this thesis for her Masters in Science at the Department of Tropical Diseases, Botucatu School of Medicine, São Paulo State University, UNESP, Botucatu, São Paulo, Brazil, 2007.

\section{Advisor: Professor Ângela Maria V. C. Soares}

ABSTRACT: Interleukin-15 is a pro-inflammatory cytokine produced by a wide range of different cell types, especially monocytes and macrophages, in response to infective agents, playing a crucial and modulatory role in innate and adaptive immune response. Infections by intracellular microorganisms such as some bacteria, protozoa and fungi point out the role of IL-15 in the activation of monocytes/macrophages and neutrophils, a process that represents an important defense mechanism in early periods of infection during the development of innate immune response. The aims of the present study were to evaluate the effects of IL15 on human neutrophil fungicidal activity against a high virulent Paracoccidioides brasiliensis strain $(\mathrm{Pb} 18)$ and to verify whether this activity was mediated by oxidative metabolism such as the production of superoxide anion and $\mathrm{H}_{2} \mathrm{O}_{2}$ and if it was associated with an alteration of cytokine (IL-8 and TNF- $\alpha$ ) levels. Neutrophils from peripheral blood of healthy individuals were incubated in the presence and absence of IL-15 $(12.5-250 \mathrm{ng} / \mathrm{ml})$ for $18 \mathrm{~h}$, at $37^{\circ} \mathrm{C}$, under tension of $5 \% \mathrm{CO}_{2}$, then infected with $\mathrm{Pb} 18$ for $4 \mathrm{~h}$ and evaluated for fungicidal activity, production of superoxide anion and $\mathrm{H}_{2} \mathrm{O}_{2}$, and quantification of cytokines IL-8 and TNF- $\alpha$ in the supernatant. Preincubation of neutrophils with IL-15 induced a significant increase in the fungicidal activity of such cells in a dose-dependent manner. After activation, there was an increase in the production of superoxide anion and $\mathrm{H}_{2} \mathrm{O}_{2}$ by these cells, suggesting participation of such metabolites in fungicidal activity. Catalase inhibits fungicidal activity, confirming the role of $\mathrm{H}_{2} \mathrm{O}_{2}$ in fungus killing. However, the levels of TNF- $\alpha$ and IL-8 were not modified after incubation with IL-15, which suggests that its role is not mediated by those cytokines. Taken together, results showed that IL-15 had a modulatory effect on human neutrophils infected in vitro with a high virulent strain of $P$. brasiliensis, which was characterized by an increased fungicidal activity mediated by a dependent mechanism of oxidative metabolism.

KEY WORDS: neutrophils, IL-15, Paracoccidioides brasiliensis, superoxide anion, $\mathrm{H}_{2} \mathrm{O}_{2}$, fungicidal activity.

\section{CORRESPONDENCE TO:}

ELISANDRA GARCIA TAVIAN, Departamento de Microbiologia e Imunologia, Instituto de Biociências de Botucatu, 18618-970, Botucatu, SP, Brasil. Phones: +55 1438116058 and +55 143811 6240. Email: garcia elis@yahoo.com.br. 